\title{
Abnormal emotional learning in a rat model of autism exposed to valproic acid in utero
}

\author{
Anwesha Banerjee, Crystal T. Engineer, Bethany L. Sauls, Anna A. Morales, Michael P. Kilgard and \\ Jonathan E. Ploski*
}

School of Behavioral and Brain Sciences, University of Texas at Dallas, Richardson, TX, USA

\author{
Edited by: \\ Katharina A. Braun, \\ Otto-von-Guericke University, \\ Germany \\ Reviewed by: \\ Markus Wöhr, Philipps-University of \\ Marburg, Germany \\ Randal Moldrich, University of \\ Queensland, Australia \\ Chan Young Shin, Konku University, \\ South Korea \\ *Correspondence: \\ Jonathan E. Ploski, Department of \\ Molecular and Cell Biology, School \\ of Behavioral and Brain Sciences, \\ Cognition and Neuroscience \\ Program, University of Texas at \\ Dallas, 800 W. Campbell Rd., GR 41, \\ Richardson, TX 75080-3021, USA \\ e-mail: jonathan.ploski@utdallas.edu
}

Autism Spectrum Disorders (ASD) are complex neurodevelopmental disorders characterized by repetitive behavior and impaired social communication and interactions. Apart from these core symptoms, a significant number of ASD individuals display higher levels of anxiety and some ASD individuals exhibit impaired emotional learning. We therefore sought to further examine anxiety and emotional learning in an environmentally induced animal model of ASD that utilizes the administration of the known teratogen, valproic acid (VPA) during gestation. Specifically we exposed dams to one of two different doses of VPA (500 and $600 \mathrm{mg} / \mathrm{kg}$ ) or vehicle on day 12.5 of gestation and examined the resultant progeny. Our data indicate that animals exposed to VPA in utero exhibit enhanced anxiety in the open field test and normal object recognition memory compared to control animals. Animals exposed to $500 \mathrm{mg} / \mathrm{kg}$ of VPA displayed normal acquisition of auditory fear conditioning, and exhibited reduced extinction of fear memory and normal litter survival rates as compared to control animals. We observed that animals exposed to $600 \mathrm{mg} / \mathrm{kg}$ of VPA exhibited a significant reduction in the acquisition of fear conditioning, a significant reduction in social interaction and a significant reduction in litter survival rates as compared to control animals. VPA $(600 \mathrm{mg} / \mathrm{kg})$ exposed animals exhibited similar shock sensitivity and hearing as compared to control animals indicating the fear conditioning deficit observed in these animals was not likely due to sensory deficits, but rather due to deficits in learning or memory retrieval. In conclusion, considering that progeny from dams exposed to rather similar doses of VPA exhibit striking differences in emotional learning, the VPA model may serve as a useful tool to explore the molecular and cellular mechanisms that contribute to not only ASD, but also emotional learning.

Keywords: autism, learning, memory, valproic acid, amygdala, emotion, Pavlovian fear conditioning

\section{INTRODUCTION}

Autism Spectrum Disorders (ASD) are complex neurodevelopmental disorders characterized by repetitive behavior and impaired communication and social interactions. Despite these common areas of impairment that define ASD as a syndrome, the clinical presentation and severity of these core symptoms vary widely across ASD individuals. In addition to these core symptoms, ASD individuals often exhibit varying levels of intellectual functioning, with some ASD individuals exhibiting high IQs, while others exhibit profound intellectual disability (Miller and Ozonoff, 2000; Munson et al., 2008; Charman et al., 2011; Green et al., 2013b). Furthermore, a significant number of ASD individuals display maladaptive emotional responses. Numerous studies indicate that a subset of ASD individuals display higher levels of anxiety (Evans et al., 2005; Weisbrot et al., 2005; Gaigg and Bowler, 2007; Wolff and Symons, 2013) and impaired emotional learning (Gaigg and Bowler, 2007; South et al., 2011, 2012). A number of theories attribute this altered emotionality to abnormalities in brain networks that mediate social-cognitive processes such as face processing and empathy (Schultz, 2005; Bachevalier and Loveland, 2006; Chevallier et al., 2012). However the underlying mechanism causing such altered emotions remains largely unknown.

ASD is a highly heritable disorder (Bailey et al., 1995; Amir et al., 1999; Marshall et al., 2008; Hallmayer et al., 2011), but for most cases of ASD, it remains unclear which genes are important for the development of ASD and how these genes interact with environmental factors to induce ASD. Most of the existing animal models of ASD were created by targeting a single gene for disruption (Zhao et al., 2005; Adachi et al., 2009; Mao et al., 2009; Umeda et al., 2010). However; the recent upsurge of clinical cases of idiopathic ASD suggests that environmental teratogens could be an important factor in the development of ASD (Christianson et al., 1994; Moore et al., 2000; Rasalam et al., 2005) and, therefore, environmental models of ASD are an important tool for uncovering the neurobiological basis of ASD. One such model is the valproic acid (VPA) animal model of ASD (Rodier et al., 1997; Arndt et al., 2005; Kim et al., 2011). This model is based on the discovery that when the anticonvulsant drug, VPA, is administered to women during their first trimester of pregnancy, they 
are much more likely to have children with ASD and intellectual disability (Vorhees, 1987; Christianson et al., 1994; Kemper and Bauman, 1998; Moore et al., 2000; Rasalam et al., 2005). In this animal model, pregnant dams are administered a single dose of VPA on or around embryonic day 12.5 of gestation, during the time of neural tube closure. The resultant progeny display anatomical and behavioral abnormalities similar to human ASD (Rodier et al., 1996; Ingram et al., 2000; Schneider and Przewlocki, 2005; Schneider et al., 2008).

The core symptoms of ASD have been extensively studied using the VPA ASD animal model. Most of these studies examined progeny from dams that were exposed to either one of two different doses of VPA (500 and $600 \mathrm{mg} / \mathrm{kg}$ ) (Schneider and Przewlocki, 2005; Schneider et al., 2007, 2008; Edalatmanesh et al., 2013; Kataoka et al., 2013; Kerr et al., 2013). A number of studies have examined how in utero exposure to VPA influences emotional learning. Of these studies, the most consistent observation is that progeny from dams exposed to $500 \mathrm{mg} / \mathrm{kg}$ of VPA on embryonic day 12.5 exhibit a reduction in fear extinction compared to progeny from saline exposed dams (Markram et al., 2008; Lin et al., 2013; Wang et al., 2013). These three studies and an additional study that examined progeny from dams exposed to VPA $600 \mathrm{mg} / \mathrm{kg}$ (Sui and Chen, 2012) also indicate that fear learning may be enhanced due to in utero VPA exposure. However, variability in the exact nature of the findings these studies report indicates that the VPA induced fear learning phenomenon may be more inconsistent or a less robust phenomenon compared to the reduced fear extinction phenomenon.

Because the VPA ASD animal model provides a unique avenue to examine the molecular basis of emotional learning and autism, we began to examine emotional learning using this model. We found that progeny from dams exposed to VPA $600 \mathrm{mg} / \mathrm{kg}$ exhibited impaired fear learning. This was a replicable phenomenon that we reproduced across cohorts of animals. When we examined progeny from dams exposed to VPA $500 \mathrm{mg} / \mathrm{kg}$, we observed that these animals exhibited reduced fear extinction, which is consistent with previous findings (Markram et al., 2008; Lin et al., 2013; Wang et al., 2013). These are intriguing results in part because the 500 and $600 \mathrm{mg} / \mathrm{kg}$ doses of VPA are very similar. It has been shown previously that there is a dose dependent difference in fetal reabsorption when dams are administered VPA at 500 and $600 \mathrm{mg} / \mathrm{kg}$ dose respectively, indicating that these doses differ substantively in how they influence development (Favre et al., 2013). Interestingly some studies have found that ASD individuals have a reduced ability to be fear conditioned (Gaigg and Bowler, 2007; South et al., 2011, 2012), therefore indicating that the VPA $600 \mathrm{mg} / \mathrm{kg}$ dose may arguably be a more relevant dose to use for examining the biological basis of autism. Here we describe our results and discuss our findings.

\section{METHODS}

\section{SUBJECTS}

Sprague Dawley rats (Charles River Laboratories) were maintained on a $12 \mathrm{~h} \mathrm{light/dark} \mathrm{cycle.} \mathrm{Food} \mathrm{and} \mathrm{water} \mathrm{were} \mathrm{provided} \mathrm{ad} \mathrm{libi-}$ tum throughout the experiment. Animal use procedures were in accordance with the National Institutes of Health Guide for the Care and Use of Laboratory Animals and were approved by the
University of Texas at Dallas Animal Care and Use Committee. To obtain progeny exposed to either VPA or saline in utero, rats were mated overnight and pregnancy was determined by the presence of a vaginal plug (E1). Female rats were used only once for breeding. Male rats were used twice for breeding, but each female the male was mated with, were placed in different experimental groups. VPA was dissolved in $0.9 \%$ saline at a concentration of $250 \mathrm{mg} / \mathrm{ml}$ and the dams were given a single intraperitoneal injection of either $600 \mathrm{mg} / \mathrm{kg}$ of VPA in $0.9 \%$ saline (VPA-Hi), $500 \mathrm{mg} / \mathrm{kg}$ of VPA in $0.9 \%$ saline (VPA-Lo), or $0.9 \%$ saline alone on day E12.5 of pregnancy as previously described (Schneider and Przewlocki, 2005; Markram et al., 2008). All dams were housed individually and left undisturbed until they gave birth. The offspring were weaned on postnatal day (PD) 21 and animals of either sex were group housed (3-4 animals). Male offspring from a total of 30 saline litters (138 male rats), 31 VPA-Hi litters (91 male rats), and 12 VPA-Lo litters (77 male rats) were used for behavior experiments (PD65-90). At PD60, the animals were individually housed and handled for $5 \mathrm{~min}$ per day for 4 days and on the 5th day behavioral experimentation began. Animals were housed individually for the duration of experimentation. The behavior experiments were performed on animals from multiple litters to limit the possibility that our results are due to natural behavioral variability that may occur between litters (Lazic and Essioux, 2013). Table $\mathbf{S 1}$ contains the litter and cohort data that were used for each experiment including the order of experiments performed on each cohort/litter. Experiments that involved subjecting rats to pain were performed after less stressful experiments (i.e., open field, object recognition). Litter survival rate was determined for cohorts $4,5,7$, and 8 by determining the ratio of the total number of pups that reached the weaning age to total number of pups born per litter. Average litter size per cohort was calculated for cohorts $1-6$, and was based on the final number of pups that were alive at weaning. No animals died prematurely following weaning and all animals post-weaning appeared healthy. Individual experiments were performed in a single session in a counterbalanced fashion with respect to control and treated animals.

\section{AUDITORY FEAR CONDITIONING}

A Coulbourn Instruments fear conditioning system with computer controlled shockers, USB cameras for video monitoring/video capture and FreezeFrame Software (Actimetrics) for unbiased behavioral analysis was used to auditory fear condition rats and to test for conditioned fear responses. Training: Rats were auditory fear conditioned with a single trial consisting of a $180 \mathrm{~s}$ acclimation period (pre-shock period) followed by the presentation of a $30 \mathrm{~s}, 5 \mathrm{kHz}, 75 \mathrm{~dB}$ tone that co-terminated with a $1 \mathrm{~s}, 0.75 \mathrm{~mA}$ foot shock in a dimly lit training chamber. Animals remained in the training chamber for an additional minute following the delivery of the foot shock (post-shock period). During the last $50 \mathrm{~s}$ of this period, the freezing behavior of each animal was measured [Post-shock freezing (PSF)] and subsequently the animals were placed back into their home cages. Short term memory (STM): Animals were tested for retention of STM $3 \mathrm{~h}$ post fear conditioning in a novel context which had distinct tactile, olfactory and visual cues compared to the auditory fear conditioning 
training chamber. STM testing consisted of a 1 min acclimation period followed by the presentation of two $(30 \mathrm{~s}, 5 \mathrm{kHz}, 75 \mathrm{~dB})$ tones with an inter-trial interval of $2 \mathrm{~min}$. Following the second tone, animals remained in the box for an additional $2 \mathrm{~min}$ and were subsequently returned to their home cages. Long term memory (LTM): Animals were tested for long term memory (LTM) $24 \mathrm{~h}$ post auditory fear training in the same context where STM was tested. Testing consisted of a 2 min acclimation period followed by the presentation of $10(20 \mathrm{~s}, 5 \mathrm{kHz}, 75 \mathrm{~dB})$ tones with an inter-trial interval of $2 \mathrm{~min}$. After the presentation of the last tone, animals remained in the box for an additional $1 \mathrm{~min}$ and were subsequently returned to their home cages. Auditory fear extinction: Fear extinction was tested on days 4 and 5 following auditory fear conditioning, in the same chambers where STM and LTM were tested previously. Testing consisted of a 2 min acclimation period followed by the presentation of $10(20 \mathrm{~s}, 5 \mathrm{kHz}, 75 \mathrm{~dB})$ tones with an inter trial interval of $2 \mathrm{~min}$. After the presentation of the last tone, animals remained in the chamber for an additional $1 \mathrm{~min}$ and were subsequently returned to their home cages. All trials were recorded using Freeze frame software. All testing occurred in chambers that were not illuminated. The absence of any movement excluding respiration was recorded as a freezing response, which was calculated by the automated Freeze frame software.

\section{FOOT SHOCK SENSITIVITY}

To evaluate sensitivity to foot shock, animals were placed in a chamber with shock grids and exposed to different intensities of foot shock ranging from 0.1 to $1.0 \mathrm{~mA}$. The lowest shock intensity at which the animals reacted by flinching or jumping was considered the threshold for shock sensitivity. Scoring of foot shock sensitivity was performed by two trained observers blind to the experiment.

\section{HOT PLATE PAIN SENSITIVITY}

The threshold for pain sensitivity was assessed using a hot-plate analgesia meter (ITC Life Sciences). The hot-plate was set to a temperature of $55^{\circ} \mathrm{C}$ and the latency to hind paw lick was measured by an observer blind to the experiment.

\section{ANXIETY/LOCOMOTOR BEHAVIOR}

General anxiety/innate fear and locomotor behavior were examined in an open field. The open field apparatus consisted of a wooden rectangular $(1.2 \times 1.2 \mathrm{~m})$ box. The periphery of the box was designated as the outer $0.30 \mathrm{~m}$ region of the box and the center zone was designated as the $0.6 \times 0.6 \mathrm{~m}$ square region at the center of the box. Each animal was placed in a corner of the box and allowed to freely explore the field for $8 \mathrm{~min}$ in low light $(\sim 100$ Lux) while being video recorded using a USB camera. After the session, the animal was removed from the apparatus and returned to the home cage and the open field apparatus was cleaned with $10 \%$ ethanol and allowed to dry completely between trials. Total entries to the center of the open field, amount of time spent in the center, distance traveled in the center, and mean distance traveled for each animal were calculated by the automated behavioral tracking system, ANYmaze (Stoelting). The total distance traveled for each animal was used to compare overall locomotory behavior between the groups. Differences in open field center entries, center time and center distance traveled between the groups were used to determine if there were differences in anxiety/innate fear.

\section{AUDITORY TONE THRESHOLD}

Multi-unit responses to tones were collected from primary auditory cortex (A1) as in previous studies (Engineer et al., 2014a,b). Rats were anesthetized with $50 \mathrm{mg} / \mathrm{kg}$ pentobarbital and placed in a custom head holder that does not obstruct the ears in a double-walled sound chamber. Rats received supplemental doses of $8 \mathrm{mg} / \mathrm{mL}$ pentobarbital during the recordings in order to maintain a state of areflexia. EKG and pulse oximetry were used to monitor heart rate and oxygen saturation. Four parylene-coated tungsten microelectrodes ( $2 \mathrm{M} \Omega$, FHC) were simultaneously lowered orthogonally into the cortex to record action potentials. In order to maximally activate contralateral (right) auditory cortex, the speaker (Tucker-Davis Technologies FF1 speaker) was positioned $90^{\circ}$ left of the midline. Tucker-Davis Technologies neurophysiology hardware and software (RA16 and RX5; SigGen and Brainware) were used for stimulus presentation and data acquisition. Auditory cortex in the rat can be reliably located using the lateral suture and underlying blood vessels as landmarks. A1 is located $\sim 1 \mathrm{~mm}$ dorsal to the horizontal portion of the suture and $\sim 1.5 \mathrm{~mm}$ posterior to the vertical portion of the suture (Kilgard and Merzenich, 1999). As in our earlier studies, recordings were made in layers IV/V of primary auditory cortex, and the location of each site was chosen to avoid damaging blood vessels (Perez et al., 2013; Centanni et al., 2014). A1 sites were defined by the well-defined tonotopy and short latency responses (Polley et al., 2007). Tone frequency intensity tuning curves $(1-32 \mathrm{kHz}$ in 0.125 octave steps \& $0-75 \mathrm{~dB}$ SPL in $5 \mathrm{~dB}$ steps) were recorded at each A1 site using an interstimulus interval of $0.5 \mathrm{~s}$.

\section{OBJECT RECOGNITION TEST}

The object recognition task was conducted as described previously (Frick and Gresack, 2003; Fernandez et al., 2008). Briefly, this task consisted of a habituation phase, sample phase, and choice phase and each of these were conducted on separate days. During the habituation phase, animals were placed in an empty rectangular box $(60 \mathrm{~cm} \mathrm{~W} \times 60 \mathrm{~cm} \mathrm{~L} \times 47 \mathrm{~cm} \mathrm{H})$ and allowed to freely explore for $5 \mathrm{~min}$. Twenty-four hours later the sample phase of the experiment was conducted, where animals were placed in the same empty rectangular box and allowed to freely explore for $2 \mathrm{~min}$, and then placed in a holding cage while two identical objects were placed in the left and right side $(5 \mathrm{~cm}$ from the walls) of the box. Animals were then immediately returned to the box and allowed to freely investigate until they accumulated a total of $30 \mathrm{~s}$ exploring the objects. Contact with either object using front paws or nose was considered as exploration of the object. After $24 \mathrm{~h}$, object recognition memory was examined during the choice phase of the experiment, using the same procedure as in sample phase except that a novel object was substituted for one of the familiar training objects. Novel object location was counterbalanced across animals. Time spent with each object was recorded using ANYmaze software (Stoelting). Animals inherently prefer to explore novel objects; thus, a preference for the 
novel object [more time than chance ( $15 \mathrm{~s}$ ) with the novel object] indicates intact memory for the familiar object. The use of 30-s total exploration time rather than fixed trial duration minimizes confounding influences of group differences in activity.

\section{SOCIAL INTERACTION}

Social interaction between rats was measured using a modified version of protocol similar to one described previously (Golden et al., 2011; Green et al., 2013a). On Day 1, the subject rat, (VPA or saline exposed rat) was habituated to the empty social interaction apparatus $(61 \times 61 \mathrm{~cm}$ gray box $)$ for $5 \mathrm{~min}$. On day 2 , a wired enclosure was placed in the corner of the social interaction box and a novel test rat was placed inside this enclosure. The subject rat was then introduced into the social interaction box and allowed to interact with the novel test rat for $10 \mathrm{~min}$. This allowed the measurement of social behavior initiated by the subject rat only. The region surrounding the novel test rat chamber was marked as the social interaction zone. The amount of time spent in the social interaction zone sniffing and exploring the test rat, the latency to the first entry into the social interaction zone, and the longest visit to the social interaction zone were recorded by ANYmaze software and these were considered measures of social interaction behavior. Mean distance traveled in the apparatus measured the overall locomotory behavior of the animals.

\section{STATISTICAL ANALYSIS}

Results were expressed as mean \pm standard error of the mean (SEM) in the text and figures. A One-Way ANOVA for repeated measurements were used to calculate the statistical significance for all fear conditioning experiments. A One-Way ANOVA was used to calculate the statistical significance for all litter survival rate differences among Saline, VPA-Lo and VPA-Hi groups. A student's $t$-test was used to compare means between groups. Differences with $p<0.05$ were considered statistically significant.

\section{RESULTS \\ PROGENY FROM VPA EXPOSED DAMS EXHIBIT A DOSE DEPENDENT EFFECT ON FEAR LEARNING}

We investigated emotional learning using a Pavlovian auditory fear conditioning paradigm using progeny from dams treated with either $500 \mathrm{mg} / \mathrm{kg}$ (VPA-Lo) or $600 \mathrm{mg} / \mathrm{kg}$ (VPA-Hi) of VPA on embryonic day 12.5. In our first experiment, VPA-Hi and saline exposed animals were auditory fear conditioned to a $30 \mathrm{~s}$, $5 \mathrm{kHz}, 75 \mathrm{~dB}$ tone that co-terminated with a $0.75 \mathrm{~mA}$ foot shock. Pre-shock freezing levels between the VPA-Hi and saline exposed animals were not significantly different $\left[t_{(27)}=1.05, p=0.30\right]$ (Figure 1A). The PSF levels were significantly higher in both groups compared to pre-shock freezing levels indicating both groups were conditioned $\left[t_{(24)}=-6.00, p<0.0001\right]$, however PSF levels were significantly lower in VPA-Hi exposed animals compared to saline exposed animals $\left[t_{(27)}=3.30, p=0.002\right]$ indicating VPA-Hi exposed animals exhibited a reduced fear response either due to decreased acquisition of fear learning or inhibition of expression of fear (Figure 1A). Three hours following fear conditioning training, retention of STM was assessed by exposing the rats to two $5 \mathrm{kHz}, 75 \mathrm{~dB}$ tones within a novel context and subsequently determining the freezing behavior of each rat, to each tone. The VPA-Hi animals exhibited significantly reduced freezing behavior as compared to the saline control group as revealed by a repeated measure ANOVA $\left[F_{(1,27)}=8.129, p=\right.$ $0.008]$ ( $\mathrm{sal}=16, \mathrm{VPA}-\mathrm{Hi}=13$ ) (Figure 1B). Twenty four hours following fear conditioning training, LTM was assessed in a similar manner as STM was, but freezing behavior was assessed during the presentation of ten, $5 \mathrm{kHz}, 75 \mathrm{~dB}$ tones. The ANOVA indicated a significant effect for group $\left[F_{(1,27)}=11.60, p=0.002\right]$, where the VPA-Hi group exhibited significantly reduced freezing behavior compared to the saline control group ( $\mathrm{sal}=16, \mathrm{VPA}-\mathrm{Hi}=13$ ) (Figure 1C). These data collectively represent the combined data from two independent cohorts of animals that essentially produced the same results underscoring the reproducibility of these results. These data for each cohort are displayed separately in Image 1. Collectively VPA-Hi exposed animals exhibit impaired PSF, STM, and LTM relative to saline exposed animals.

Next, we examined VPA-Lo exposed animals for their ability to be auditory fear conditioned. VPA-Lo and saline exposed animals were fear conditioned and PSF, STM, and LTM were assessed in the same manner as mentioned above. VPA-Lo and saline exposed animals did not exhibit differences in pre-shock freezing levels $\left[t_{(22)}=0.84, p=0.40\right]$ or PSF levels $\left[t_{(22)}=1.55\right.$, $p=0.13$ ]. However both groups exhibited significantly higher PSF levels compared to pre-shock freezing levels $\left[t_{(22)}=-9.79\right.$, $p<0.0001]$ (Figure 1D). These data indicate that acquisition of fear conditioning was normal in VPA-Lo exposed animals. Freezing levels during the STM test were measured and ANOVA revealed that the effect for group $\left[F_{(1,22)}=0.001, p=0.978\right]$, were not significant indicating that the freezing levels during the STM test were not different between the VPA-Lo and the saline control groups $(\mathrm{sal}=12, \mathrm{VPA}-\mathrm{Lo}=12)($ Figure 1E). Twenty four hours after fear conditioning training, freezing levels during the LTM test were assessed. ANOVA indicated that freezing levels for the VPA-Lo and saline groups during the LTM test did not differ significantly as there was no effect for group $\left[F_{(1,22)}=0.029\right.$, $p=0.86],($ sal $=12$, VPA-Lo $=12)($ Figure $1 F)$. Therefore in contrast to the VPA-Hi exposed animals that exhibited significantly impaired PSF, STM, and LTM relative to saline controls, VPA-Lo exposed animals did not differ in PSF, STM, and LTM relative to saline controls.

\section{PROGENY FROM VPA-LO EXPOSED DAMS EXHIBIT REDUCED FEAR EXTINCTION TO A CONDITIONED AUDITORY CUE}

Our previous experiment demonstrated that VPA-Lo exposed rats exhibit intact STM and LTM relative to saline controls, 3 and $24 \mathrm{~h}$ post fear conditioning respectively. However, a previous study indicated that rats exposed to $500 \mathrm{mg} / \mathrm{kg}$ (VPA-Lo) in utero, exhibit elevated conditioned fear memory, and reduced fear extinction (Markram et al., 2008; Lin et al., 2013; Wang et al., 2013). Therefore, in our next experiment, we wanted to determine if in our laboratory, VPA-Lo animals display reduced fear extinction. VPA-Hi exposed animals were excluded from this experiment since they failed to acquire normal levels of fear memory. To examine auditory fear extinction rates between VPA-Lo and saline exposed animals, we measured conditioned tone fear memory on day 4 and day 5 post fear conditioning by subjecting 

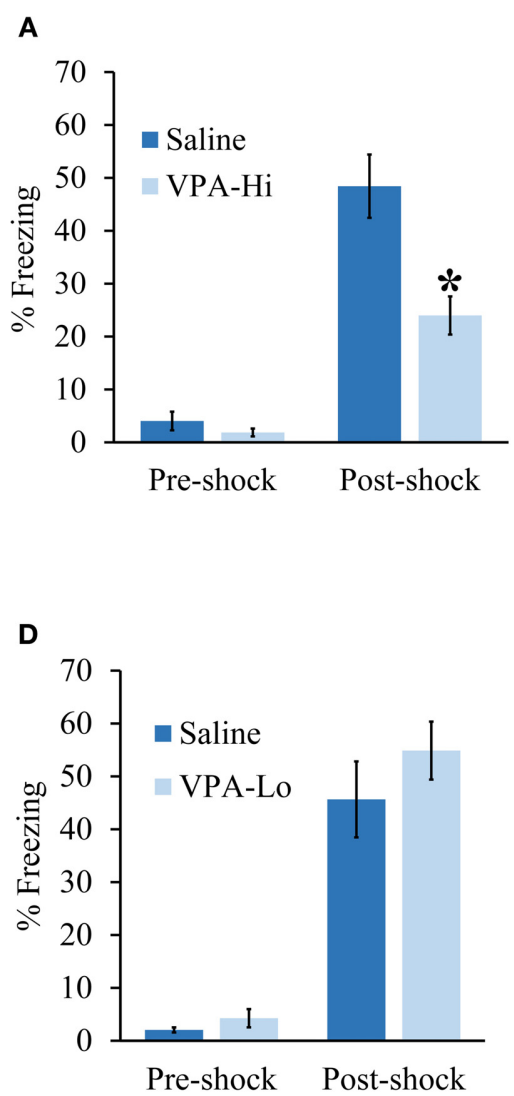

FIGURE 1 | Progeny from VPA exposed dams exhibit a dose dependent effect on fear learning: (A-C) Progeny from VPA-Hi and saline exposed dams were auditory fear conditioned (Saline $=16$, VPA-Hi = 13). (A) Pre and post shock freezing was assessed immediately before and after exposure to tone-shock, respectively. (B) Auditory fear memory assessed $3 \mathrm{~h}$ post fear conditioning (i.e., STM) (C) Auditory fear memory assessed $24 \mathrm{~h}$ post fear conditioning (i.e.,
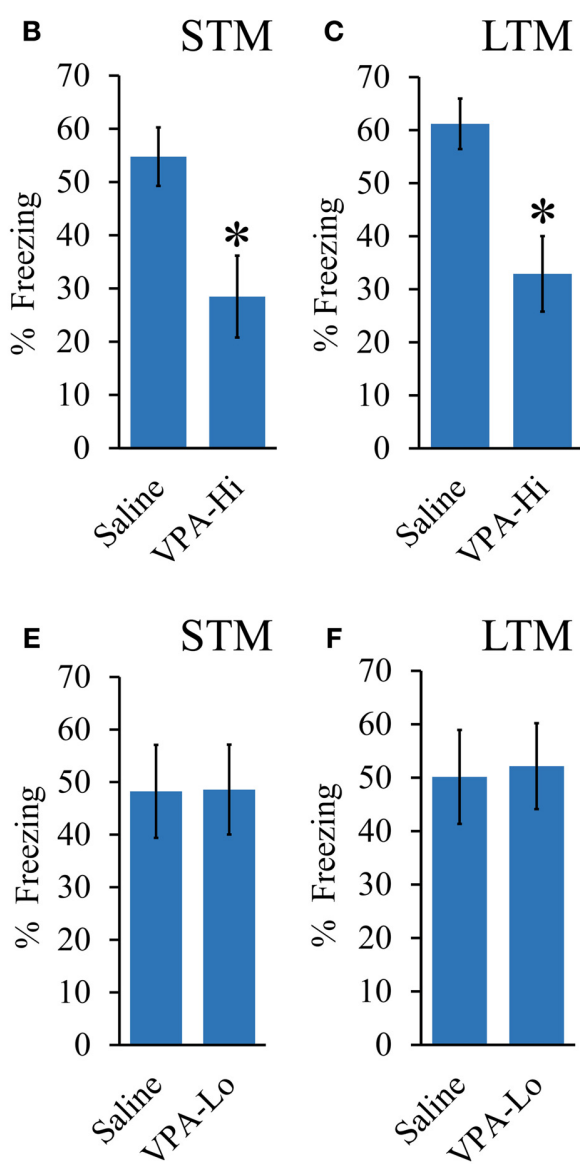

LTM). (D-F) Progeny from VPA-Lo and saline exposed dams were auditory fear conditioned (Saline $=12$, VPA-Lo $=12$ ). (D) Pre and post shock freezing was assessed immediately before and after exposure to tone-shock, respectively. (E) Auditory fear memory assessed $3 \mathrm{~h}$ post fear conditioning (i.e., STM) (F) Auditory fear memory assessed $24 \mathrm{~h}$ post fear conditioning (i.e., LTM). Bars represent the mean \pm standard error of the mean (SEM) $\left({ }^{*} p<0.05\right)$. the rats to ten $20 \mathrm{~s}, 5 \mathrm{kHz}, 75 \mathrm{~dB}$ tones in the same context used to examine LTM. A repeated measures ANOVA revealed no effect for group $\left[F_{(1,22)}=1.12, p=0.30\right]$, indicating that on day 4 there was not a statistically significant difference in extinction rates between the VPA-Lo and saline exposed animals. However on day 5 of extinction testing the difference in freezing between the VPA-Lo and saline groups became more striking, where a significant difference for increased freezing in VPA-Lo exposed animals relative to saline controls was found $\left[F_{(1,22)}=7.26, p=0.01\right]$, $(\mathrm{sal}=12, \mathrm{VPA}-\mathrm{Lo}=12)$ (Figure 2). These findings are consistent with the view that VPA-Lo exposed animals exhibit reduced fear extinction.

\section{THE FEAR CONDITIONING DEFICIT OBSERVED IN PROGENY FROM VPA-HI EXPOSED DAMS IS LIKELY NOT DUE TO DEFICITS IN SENSORY MODALITIES NECESSARY FOR AUDITORY FEAR CONDITIONING}

Progeny from VPA-Hi exposed dams exhibited a reduced ability to be auditory fear conditioned as indicated by reduced freezing relative to saline controls during PSF, STM, and LTM tests.
However, these data could be a result of impairments in the neurobiological mechanisms that subserve learning or they could be due to sensory deficits in systems that are required for auditory fear conditioning, such as nociceptive or auditory modalities. Therefore we examined VPA-Hi and saline exposed animals for nociception and audition, using the hot plate test, shock sensitivity tests and by measuring neuronal spike firing within the auditory cortex in response to exposure to $5 \mathrm{kHz} 75 \mathrm{~dB}$ tones, respectively.

VPA and saline exposed animals were examined for nociceptive ability using the hot plate test. Animals were placed on a $55^{\circ} \mathrm{C}$ hot plate and the latency for each animal to paw lick was measured. No significant difference in latency to paw lick was found in either VPA-Lo animals $\left[t_{(18)}=0.61, p=0.54\right]$ ( $\mathrm{sal}=$ 12 , VPA-Lo $=12$ ) or VPA-Hi animals $\left[t_{(18)}=-0.19, p=0.8\right]$ $(\mathrm{sal}=12$, VPA-Hi $=11)$, in comparison to saline control animals (Figures 3A,B). These data indicate that in utero exposure to VPA at both the high and low doses does not significantly impair nociception. 


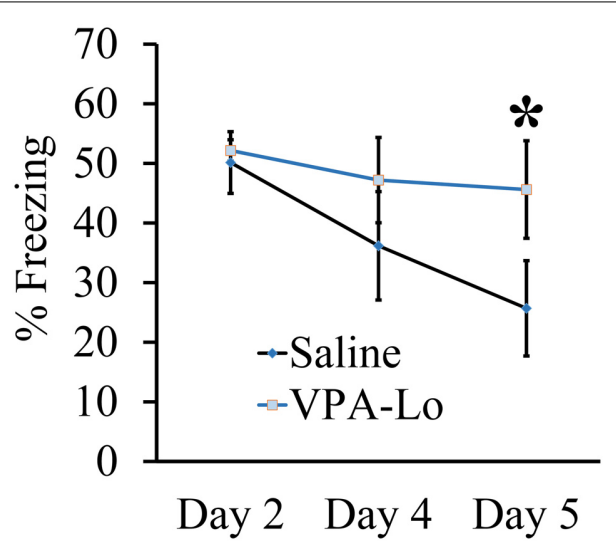

FIGURE 2 | Progeny from VPA-Lo exposed dams exhibit reduced fear extinction to a conditioned auditory cue. Progeny from VPA-Lo and saline exposed dams were auditory fear conditioned and LTM/extinction learning was assessed on days 2, 4, and 5 post fear conditioning (Saline = 12 , VPA-Lo $=12$ ). Bars represent the mean \pm s.e.m. $\left({ }^{*} p<0.05\right)$
To measure the threshold at which progeny from VPA and saline exposed dams responded to foot shock stimuli, the animals were exposed to foot shocks ranging from 1.0 to $1.0 \mathrm{~mA}$ at an increment of $0.1 \mathrm{~mA}$ and the lowest shock intensity at which the animals reacted was considered the threshold for shock sensitivity. Sensitivity to foot shocks did not differ significantly in either the VPA-Lo group $\left[t_{(22)}=0.84, p=0.40\right]$ ( $\mathrm{sal}=12$, VPALo $=11)$, or the VPA-Hi group $\left[t_{(21)}=-0.12, p=0.90\right](\mathrm{sal}=$ 10 , VPA-Hi $=10$ ), when compared to animals exposed to saline (Figures 3C,D). Overall, these data indicate that progeny from VPA-Hi, VPA-Lo and saline exposed dams exhibit similar levels of shock sensitivity and therefore the deficit in fear conditioning exhibited by the VPA-Hi group relative to saline controls is likely not due to an impaired ability to perceive the foot shock. Notably, the threshold for shock sensitivity for all groups was far below the shock intensity used for fear conditioning.

To determine whether VPA-Hi exposed animals possess impaired hearing to a $5 \mathrm{kHz}, 75 \mathrm{~dB}$ tone, we compared the action potential spike firing of neurons within the primary auditory cortex (A1) from VPA-Hi and saline exposed animals. The average

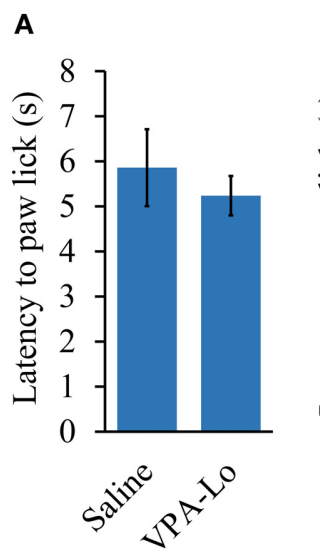

B

E
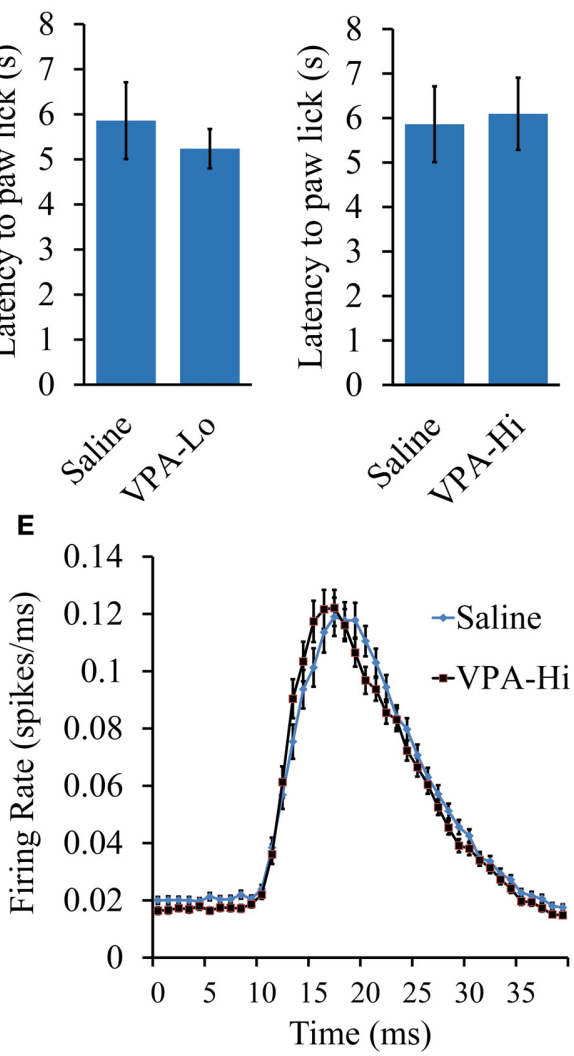

FIGURE 3 | The fear conditioning deficit observed in progeny from VPA-Hi exposed dams is likely not due to deficits in sensory modalities necessary for auditory fear conditioning. (A) Thermal nociception as measured by the hotplate test did not differ between progeny from VPA-Lo and saline exposed dams (Saline $=12$, VPA-Lo $=$ 12) (B) or progeny from VPA-Hi and saline exposed dams (Saline $=12$, VPA-Lo $=$ 11) (C) Response to foot shock stimuli did not differ between progeny from VPA-Lo and saline exposed dams (Saline $=10$

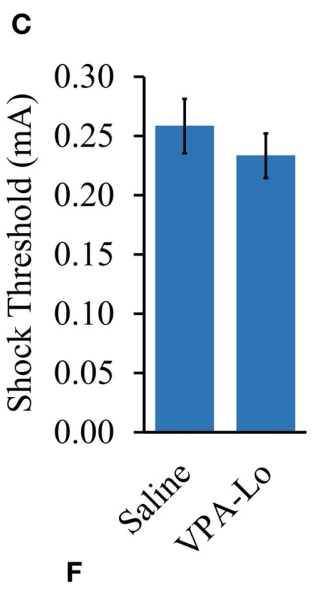

D

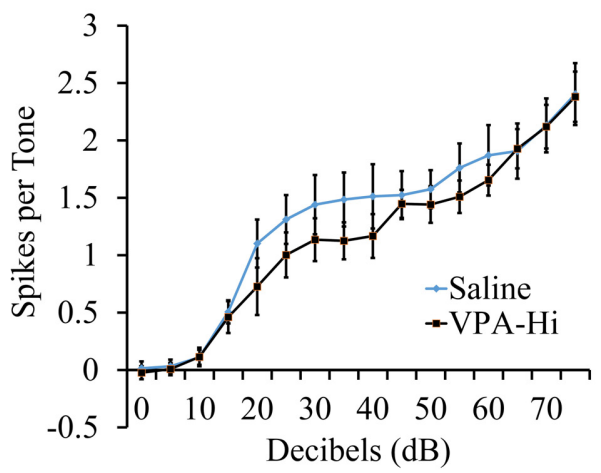

VPA-Lo $=10)($ D) or progeny from VPA-Hi and saline exposed dams (Saline $=12$, VPA-Lo $=11$ ). (E) The primary auditory cortex response strength and response latency to a $5 \mathrm{kHz}$ tone did not differ between progeny from VPA-Hi and saline exposed dams (Saline $=10, \mathrm{VPA}-\mathrm{Hi}=$ 10). (F) Hearing ability to a $5 \mathrm{kHz}, 0-75 \mathrm{~dB}$ tone did not differ between progeny from VPA-Hi and saline exposed dams (Saline $=10, \mathrm{VPA}-\mathrm{Hi}=$ 10) as measured by auditory cortex neuronal spike firing upon exposure to $5 \mathrm{kHz}, 0-75 \mathrm{~dB}$ tones. Data presented as mean \pm s.e.m. 
response amplitude evoked by tones within $1 / 4$ octave of $5 \mathrm{kHz}$ was not significantly different in VPA-Hi rats compared to saline rats $(1.26 \pm 0.06$ spikes/tone vs. $1.27 \pm 0.07$ spikes/tone, $p=0.94$, Figure 3E). There was no significant difference in the peak firing latency to tones within $1 / 4$ octave of $5 \mathrm{kHz}$ in VPA-Hi rats compared to saline rats $(19.48 \pm 0.3 \mathrm{~ms}$ vs. $20.02 \pm 0.3 \mathrm{~ms}, \mathrm{p}=0.22$, Figure $3 \mathrm{E})$. The $5 \mathrm{kHz}$ tone was presented at intensities ranging from 0 to $75 \mathrm{~dB}$, and the average number of spikes per tone was plotted by tone intensity. The response strength to tones in A1 was unimpaired in VPA exposed rats compared to saline rats $\left[F_{(1,14)}=0.64, p=0.43\right]$ thereby supporting the notion that progeny from VPA-Hi exposed dams do not exhibit impaired hearing to a $5 \mathrm{kHz}, 75 \mathrm{~dB}$ tone (Figure 3F).

\section{PROGENY FROM VPA EXPOSED DAMS EXHIBIT INCREASED ANXIETY AND NORMAL LOCOMOTOR BEHAVIOR}

The open field test was used to examine the relative level of anxiety in VPA and saline exposed animals. VPA-Hi exposed animals exhibited a reduced number of center entries $\left[t_{(43)}=\right.$ $2.42, p=0.01]$, a trend of reduced center time $\left[t_{(43)}=1.54\right.$, $p=0.13]$ and reduced center distance traveled $\left[t_{(43)}=2.24\right.$, $p=0.03]$ when compared to saline animals during their $8 \mathrm{~min}$ exploration period in the open field, indicating an increased level of general anxiety (Figures $4 \mathrm{~A}-\mathrm{C}$ ). However, the mean distance traveled $\left[t_{(43)}=-1.09, p=0.27\right]$, in the open field did not differ between VPA-Hi and saline exposed animals indicating that locomotor behavior was not significantly different between these groups (Figure 4D). VPA-Lo exposed animals also displayed a reduced number of center entries $\left[t_{(39)}=2.19, p=0.03\right.$, a reduced center time $\left[t_{(39)}=2.08, p=0.04\right]$ and reduced center distance traveled $\left[t_{(39)}=2.36, p=0.02\right]$, compared to saline animals (Figures $4 \mathrm{E}-\mathbf{G}$ ). The mean distance traveled $\left[t_{(39)}=0.68\right.$, $p=0.49$ ] in the field did not differ between VPA-Lo and saline exposed animals indicating that locomotor behavior was not different between these groups (Figure $4 \mathbf{H}$ ). Collectively progeny from VPA exposed dams exhibit higher levels of anxiety as determined by open field behavior and these results are similar to what others have found, following both VPA-Lo (Markram et al., 2008; Lin et al., 2013) and VPA-Hi exposure (Schneider and Przewlocki, 2005; Schneider et al., 2007). For unequivocal demonstration that VPA exposure induces anxiety like behavior, these animals would also need to be assessed in the elevated plus maze task.

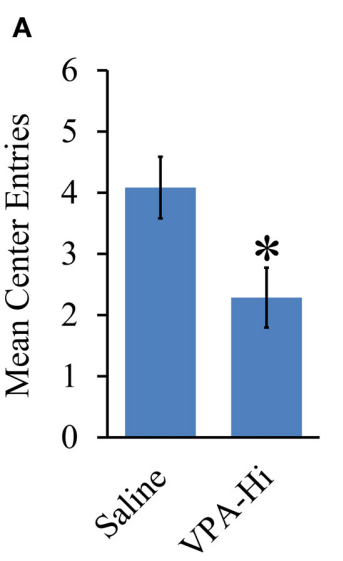

B

E

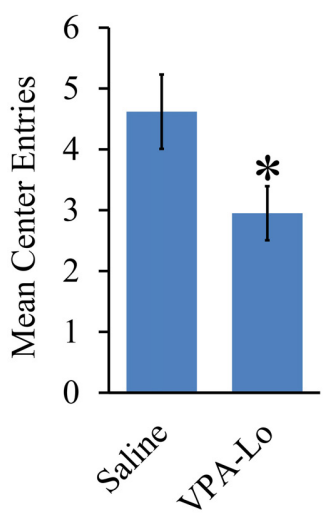

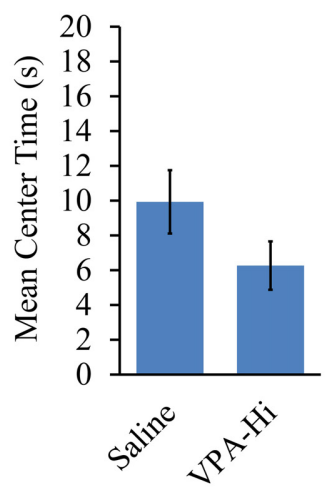

$\mathbf{F}$

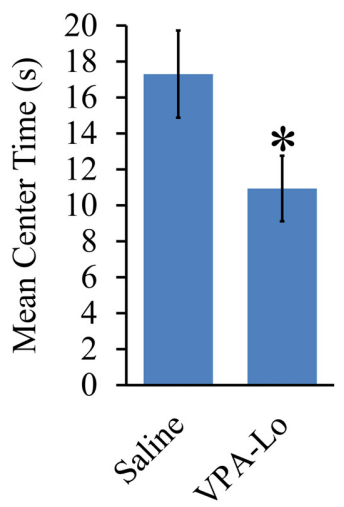

FIGURE 4 | Progeny from VPA exposed dams exhibit increased anxiety and normal locomotor behavior. Progeny from VPA-Hi dams exhibit increased anxiety in an open field as indicated by, (A) a reduced number of center entries, (B) a trend of reduced center time, (C) a reduced center distance traveled, without affecting, (D) the mean total distance traveled as compared to saline exposed animals

C

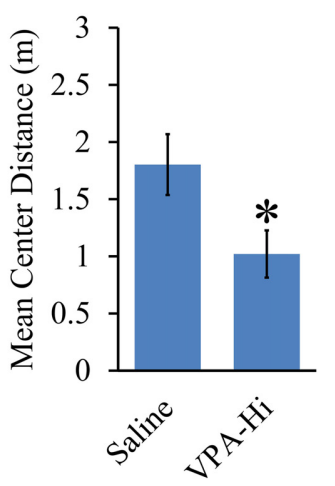

G

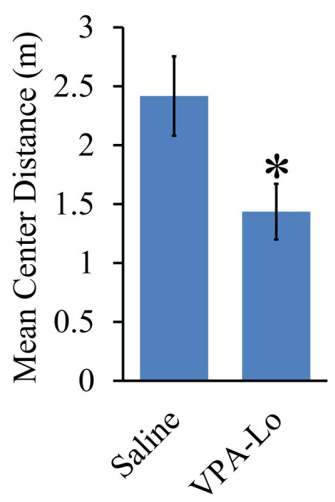

D

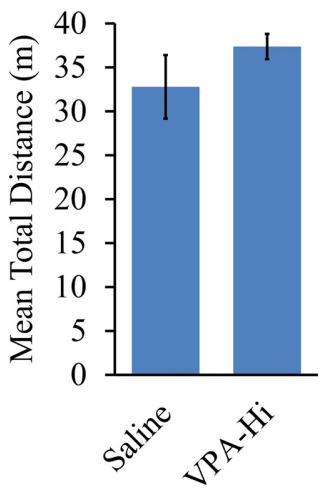

H

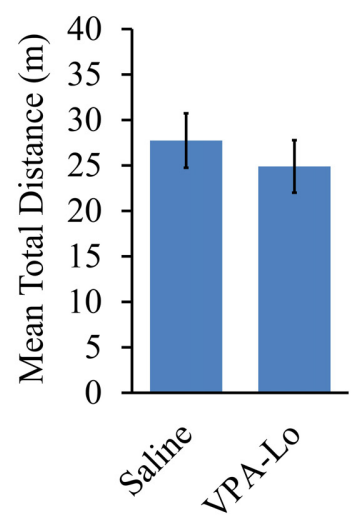

(Saline $=25$, VPA-Hi $=21$ ). Progeny from VPA-Lo exposed dams exhibit increased anxiety in an open field as indicated by, (E) a reduced number of center entries, (F) a reduced center time, (G) a reduced center distance traveled, without affecting, (H) the mean total distance traveled as compared to saline exposed animals (Saline $=21$, VPA-Lo $=20)$. Data presented as mean \pm s.e.m. $\left({ }^{*} p<0.05\right)$. 


\section{PROGENY FROM VPA EXPOSED DAMS EXHIBIT NORMAL OBJECTION RECOGNITION MEMORY}

In this experiment we wanted to determine if VPA exposed animals exhibit deficits in other forms of learning and memory in addition to deficits in associative fear learning. Specifically, we examined if VPA-Hi, VPA-Lo and saline exposed animals differ in their ability to form object recognition memory. During the sample phase, VPA-Hi and saline exposed animals were allowed to explore two identical objects situated on the left and right sides of the testing apparatus until they had accumulated $30 \mathrm{~s}$ of exploration time for these objects. Neither group exhibited within group differences for the amount of time the animals explored the left or right objects (VPA-Hi: $t_{(14)}=-1.88, p=0.08$ ]; saline: $\left[t_{(14)}=-1.26, p=0.22\right]$. Further, differences were not detected between VPA-Hi or saline exposed animals during the sample phase in the amount of time each group of animals explored the object located on the left side $\left[t_{(16)}=0.195, p=0.84\right]$ and right side $\left[t_{(16)}=-0.188, p=0.85\right]$ (Figure 5A). Twenty-four hours later, object recognition memory was examined during the choice phase of the experiment by allowing the rats to explore an object identical to what was used during the sample phase (i.e., familiar object) and a novel object for $30 \mathrm{~s}$. Both VPA-Hi $\left[t_{(14)}=2.51\right.$, $p=0.02]$ and saline $\left[t_{(18)}=2.718, p=0.01\right]$ exposed animals spent significantly more time than chance exploring the novel object, indicating they both formed object recognition memory. Additionally, VPA-Hi and saline exposed animals did not spend significantly different amounts of time with the novel object $\left[t_{(16)}=0.09, p=0.92\right]$ (Figure 5B).

Next, we examined VPA-Lo and saline exposed animals in their ability to form object memory. During the sample phase, VPA-Lo exposed animals exhibited a slight preference for the familiar object placed on the left side of the box compared to the right side $\left[t_{(18)}=2.21, p=0.04\right]$. However, differences were not detected between VPA-Lo or saline exposed animals during the sample phase in the amount of time each group explored the object located on the left side $\left[t_{(18)}=-1.63, p=0.11\right]$ and right side $\left[t_{(18)}=-1.65, p=0.11\right]$ (Figure 5C). Twenty-four hours later, object recognition memory was examined during the choice phase of the experiment by allowing the rats to explore an object identical to what was used during the sample phase (i.e., familiar object) and a novel object for $30 \mathrm{~s}$. Both VPA-Lo $\left[t_{(18)}=3.12\right.$, $p=0.005]$ and saline $\left[t_{(18)}=2.71, p=0.01\right]$ exposed animals spent significantly more time than chance exploring the novel object, indicating they both formed object recognition memory. Additionally, VPA-Lo and saline exposed animals did not spend significantly different amounts of time with the novel object $\left[t_{(18)}=-0.03, p=0.97\right]$ (Figure 5D). These data indicate that the VPA-Hi and VPA-Lo exposed animals exhibit normal object
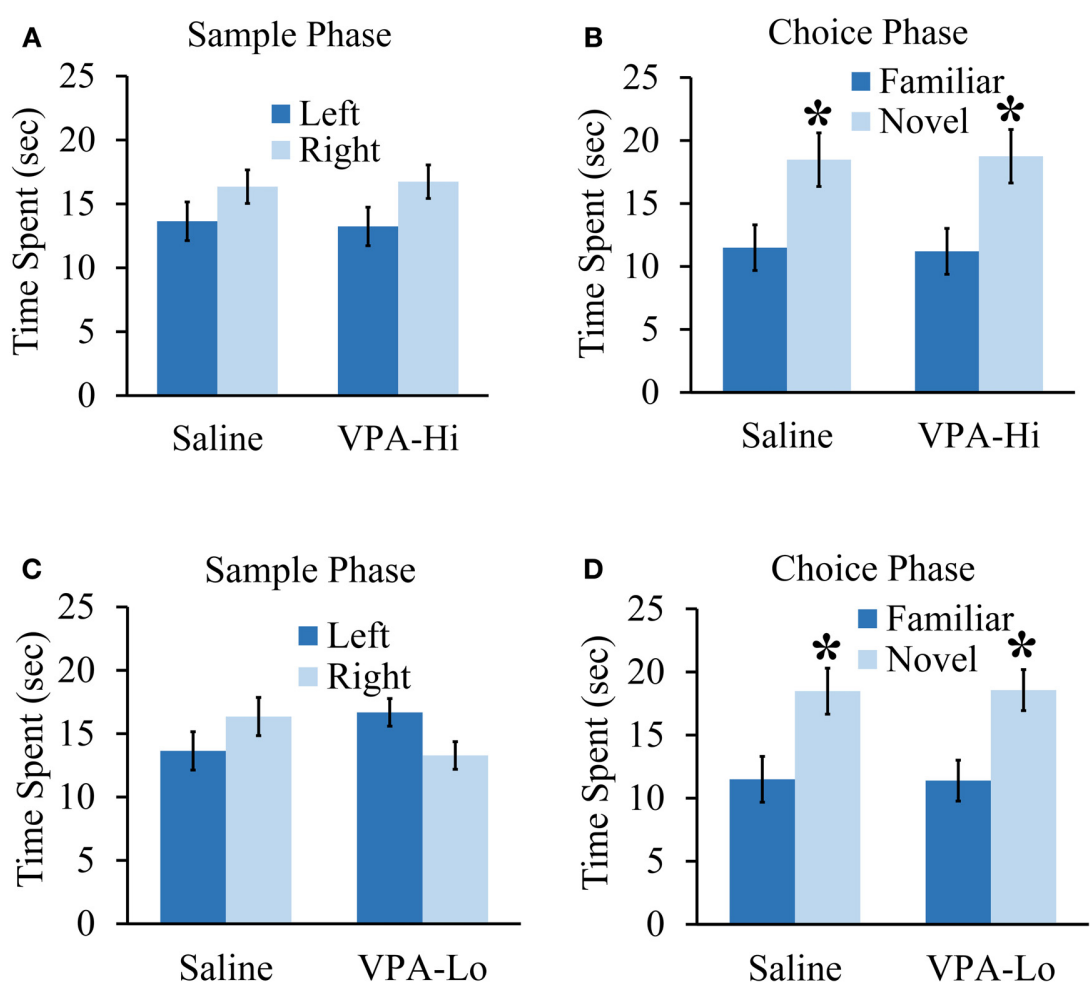

FIGURE 5 | Progeny from VPA exposed dams exhibit normal objection recognition memory. (A) Progeny from VPA-Hi and saline exposed dams spent equal time with the familiar object during the sample phase of an object recognition test (saline $=10, \mathrm{VPA}-\mathrm{Hi}=8$ ). (B) VPA-Hi and saline animals spent more time than chance with a novel object during the choice phase of an object recognition test, indicating normal retention of object

memory. (C) The VPA-Lo group had a slight preference for the object situated on left side compared to right side (saline $=10, \mathrm{VPA}-\mathrm{LO}=10$ ) (saline $=10$, VPA-Lo = 10). (D) VPA-Lo and saline exposed animals spent more time than considered chance with a novel object during the choice phase of an object recognition test, indicating normal retention of object memory. Data presented as mean \pm s.e.m. time spent with each object $\left({ }^{*} p<0.05\right)$. 
recognition memory relative to progeny from saline exposed dams. Collectively, our findings are consistent with other findings that progeny from VPA-Hi and VPA-Lo exposed dams do not exhibit deficits in object recognition memory (Schneider et al., 2007; Chomiak et al., 2014) or spatial memory (Markram et al., 2008; Bambini-Junior et al., 2011).

\section{PROGENY FROM VPA-HI EXPOSED DAMS EXHIBIT REDUCED SOCIAL INTERACTION}

We found that VPA-Hi exposed animals exhibited reduced fear learning, and this was in sharp contrast to the results we obtained from VPA-Lo animals and one previous finding that reported that animals exposed to $600 \mathrm{mg} / \mathrm{kg}$ of VPA exhibited enhanced fear learning (Sui and Chen, 2012). Therefore to be sure something was not anomalous about our VPA-Hi animals, we examined if in our hands VPA-Hi animals also exhibit autistic-like behaviors similar to what others have reported previously (Schneider and Przewlocki, 2005; Lin et al., 2013). Specifically we examined the social interaction of VPA-Hi and saline control rats with a novel test rat. We observed that VPA-Hi animals spent less time in the social interaction zone $\left[t_{(28)}=3.47, p=0.001\right]$, exhibited a higher latency of first entry into the social zone $\left[t_{(28)}=-2.35\right.$, $p=0.02]$, and exhibited shorter visits to the social interaction zone $\left[t_{(28)}=2.51, p=0.01\right]$ when compared to saline animals. The mean distance traveled in the social apparatus did not differ $\left[t_{(28)}=0.24, p=0.80\right]$, between the groups (Figures 6A-D). These data indicate that VPA-Hi animals exhibit reduced social interaction as compared to saline animals.

\section{LITTERS FROM VPA-Hi EXPOSED DAMS ARE SMALLER AND VPA-Hi EXPOSED PROGENY EXHIBIT REDUCED SURVIVAL}

We measured the effect of in utero VPA exposure on the overall litter survival rate and litter size. Across cohorts of animals, the average litter size was consistently lower for VPA-Hi treated animals compared to saline animals $\left[t_{(10)}=2.52, p=0.03\right]$ (Figure 7A). Prenatal exposure to VPA also induces a significant reduction in litter survival rate. A One-Way ANOVA revealed an overall group effect of VPA on litter survival rate $\left[F_{(2,22)}=9.72, p=0.001\right]$. Fisher's post-hoc test revealed significant reduced litter survival rate in VPA-Hi animals compared to saline animals $(p=0.0006)$ and VPA Lo animals $(p=0.01)$ (Figure 7B). These findings are consistent with observations previously reported (Favre et al., 2013) and underscore that there is a bona fide biological difference between the $500 \mathrm{mg} / \mathrm{kg}$ (VPA-Lo) and $600 \mathrm{mg} / \mathrm{kg}$ (VPA-Hi) doses of VPA.

\section{DISCUSSION}

Our findings that progeny from VPA exposed dams exhibit increased anxiety and altered emotional learning complement and expand upon previous studies from other laboratories. In particular, we provide novel data that indicate that progeny from VPA-Hi exposed dams exhibit significantly impaired acquisition of auditory fear conditioning. These findings are interesting, in part because the VPA-Lo exposed animals do not exhibit this reduction in fear learning. Given that these two rather similar

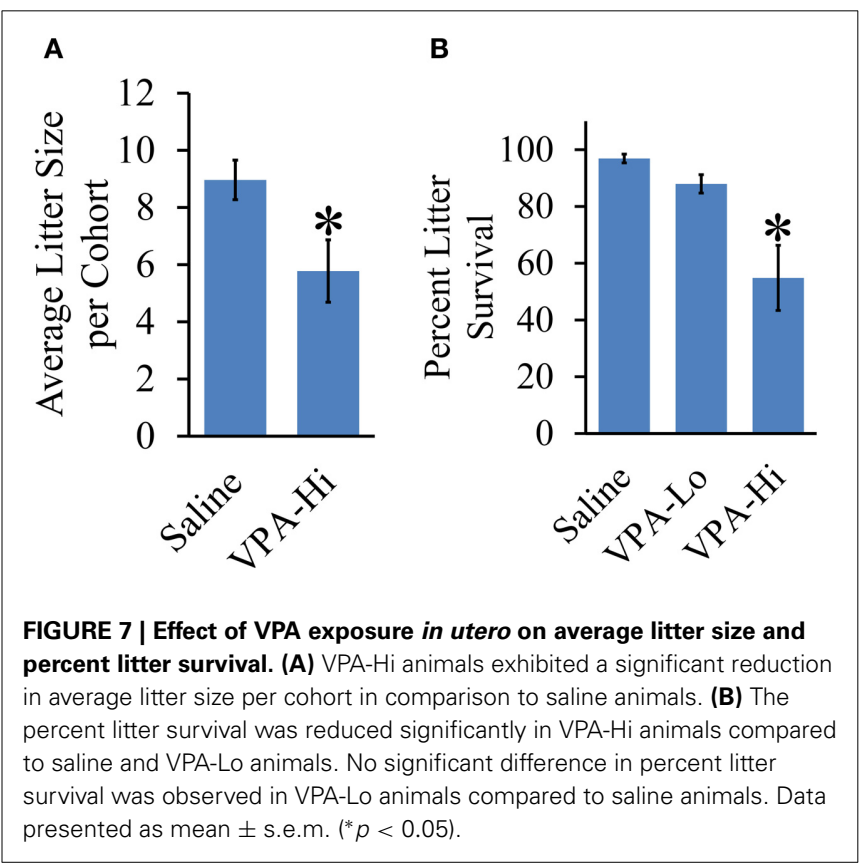

\section{A}
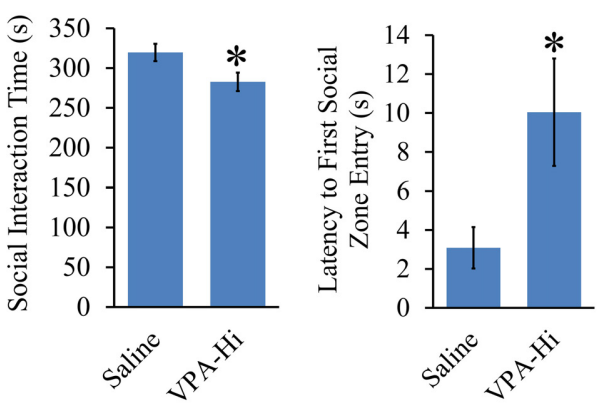

FIGURE 6 | Progeny from VPA-Hi exposed dams exhibit reduced social interaction. (A) VPA-Hi animals spent less time in the social interaction zone compared to saline animals (saline $=15, \mathrm{VPA}-\mathrm{Hi}=15$ ). (B) Latency to first entry into the social interaction zone was higher in VPA-Hi animals compared
C

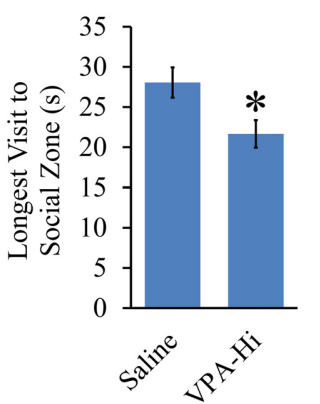

D

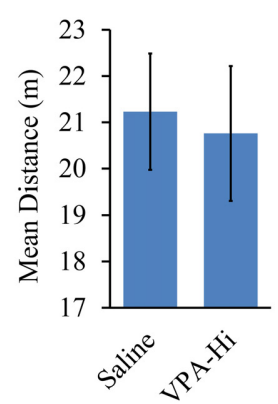

to saline animals. (C) The longest visit to the social interaction zone was reduced in VPA-Hi animals. (D) Mean distance traveled in the social interaction apparatus did not differ significantly between the groups. Data presented as mean \pm s.e.m. $\left({ }^{*} p<0.05\right)$. 
doses of VPA result in different behavioral phenomena and differences in litter sizes and pup survivability, it seems likely the VPA-Hi dose is at or near an important biological tipping point. Notably, a previous study that examined different behavioral phenomena then we have, reported a differential influence on learning using slightly lower $(470 \mathrm{mg} / \mathrm{kg}$ VPA $)$ and higher $(720 \mathrm{mg} / \mathrm{kg}$ VPA) doses of VPA, where the lower dose enhanced learning and the higher dose inhibited learning (Frisch et al., 2009). A human population study revealed a significant relationship between the dosage of VPA and human teratogenicity, with higher doses associated with greater risk for birth defects (Vajda et al., 2004). Anatomical defects were also observed in progeny of VPA exposed dams to be dose dependent (Binkerd et al., 1988). Collectively, these results are consistent with our findings.

Most of our findings are largely consistent with the prior published literature; however there are few important differences that are worth highlighting. In our study, we detected a trend, $(p=0.13)$ for enhanced learning during the training phase of fear conditioning, but did not detect differences in memory strength during the testing phases of fear conditioning for animals exposed to VPA-Lo. However, a few prior studies reported enhanced fear learning in VPA-Lo exposed animals. Intriguingly though, these studies report slightly different fear learning phenomena due to VPA-Lo exposure. For example one study found no difference in fear learning for VPA-Lo animals during the training phase of fear conditioning, but found enhanced freezing to conditioned tones during the LTM test, which the authors interpreted as stronger fear memory (Markram et al., 2008). However, it remains possible that the enhanced freezing could be due to either stronger consolidated fear memory or it could be due to reduced intra-trial fear memory extinction. Another laboratory detected enhanced fear learning for VPA-Lo animals during the training phase of fear conditioning, but their LTM data do not unambiguously indicate if the fear memory is stronger or if the animals are simply extinguishing the fear memory faster (Lin et al., 2013; Wang et al., 2013). Considering that the fear learning data from VPA-Lo exposed animals is not consistent across labs, the VPA-Lo induced enhancement of fear learning may be a less robust phenomenon as compared to the VPALo induced fear extinction deficit. For example, the finding that progeny from VPA-Lo exposed dams exhibit reduced fear memory extinction is supported by all prior studies and this study. A different study reported that VPA-Hi exposed animals exhibit enhanced learning for trace and delay fear conditioning (Sui and Chen, 2012). While it is evident that this prior study did not detect an impairment in learning, similar to what we have, it is less clear if the data reported in this prior study data truly reflect an enhancement in delay fear conditioning, since they do not find differences in freezing levels during conditioned tone presentation during STM and LTM testing between VPA and saline exposed animals. This prior study also reported that there was no difference in litter sizes and pup survivability between saline and VPA-Hi treated animals which is incongruent with our study and a prior study (Favre et al., 2013). Considering our study and the above mentioned studies utilized different fear conditioning parameters, fear memory testing parameters and in some cases different strains of rats and age of rats, it is certainly possible that we simply observed slightly different phenomena. Notably differences in VPA induced effects have been found to be dependent on genetic background (Downing et al., 2010), the age at which the VPA exposed animals were examined (Martin and Manzoni, 2014) and maternal stress (Ogawa et al., 2007).

Because auditory fear conditioning could be influenced by impairments in the perception of the pain normally induced by the foot shock, and impairments in hearing of the tone used to auditory fear condition the animals, we examined foot shock/pain sensitivity and hearing to the tone used to auditory fear condition the animals. Our data indicate that progeny from VPA-Hi and saline exposed dams did not exhibit significant differences in these sensory modalities, indicating that differences in fear conditioning between these groups are unlikely due to abnormalities in these sensory modalities. Others have previously found that VPA exposed animals exhibit subtle differences in pain sensitivity (Schneider and Przewlocki, 2005). However, one of the studies that reported these observations, examined thermal pain sensitivity and importantly these animals were not impaired enough in pain sensitivity for it to significantly alter foot shock induced fear conditioning (Markram et al., 2008).

VPA is one of the most widely prescribed drugs for the treatment of epilepsy. The mechanism by which VPA induces teratogenicity is currently not fully understood. Various biochemical studies indicate that VPA can suppress neuronal activity by blocking sodium and calcium channels and enhance the functioning of the inhibitory neurotransmitter, GABA, in the brain (Kwan et al., 2001; Gould et al., 2004). Further, studies have demonstrated the ability of VPA to alter gene expression in vitro and in vivo (Jergil et al., 2009; Kultima et al., 2010; Cohen et al., 2013; Oguchi-Katayama et al., 2013) and these affects have been attributed to VPA's ability to inhibit histone deacetylase (HDAC) (Phiel et al., 2001; Eyal et al., 2004; Haberland et al., 2009). HDAC plays an important role in regulating transcription during fetal development (Shaked et al., 2008; Montgomery et al., 2009). Consequently, HDAC inhibition may induce abnormal gene expression during embryogenesis, causing behavioral impairments at later time points (Phiel et al., 2001). Notably, a recent rodent study demonstrated that inhibition of HDAC in utero is sufficient to cause autism-like phenotypes including sociability deficits in exposed offspring (Moldrich et al., 2013).

Only a few studies have examined the process of fear conditioning among human ASD patients. Gaigg and Bowler (2007) observed that patients diagnosed with Asperger's syndrome displayed attenuated fear conditioning. Specifically, these individuals exhibited reduced skin conductance to conditioned aversive stimuli but normal responses to unconditioned stimuli compared to healthy controls. Another study found that the degree of social impairment observed in ASD individuals directly correlated to their ability to be fear conditioned, i.e., an individual with reduced ability to be fear conditioned had a higher level of social impairment and vice versa (South et al., 2011). It was also found that ASD individuals exhibited delayed reversal learning when a previously conditioned safety cue was changed to be a predictor of aversive stimuli (South et al., 2012). However, all 
ASD patients may not exhibit deficits in fear conditioning since one study observed that ASD individuals exhibited normal fear learning when examined using a fear potentiated startle response paradigm (Bernier et al., 2005). Nevertheless, the fact that similar fear conditioning deficits were observed in progeny from VPAHi exposed dams and a subpopulation of human ASD strongly advocates that further research is needed. Considering that ASD is a very heterogeneous disorder that likely has multiple causes, it could be useful to categorize these patients into distinct entities to facilitate the identification of the neurobiological mechanisms that underlie ASD. For example, it may be possible to screen ASD individuals for their ability to be fear conditioned and use this metric as a biomarker or endophenotype that could help categorize ASD individuals and thus serve as a way to disambiguate the heterogeneous nature of this disorder.

\section{AUTHOR CONTRIBUTIONS}

Anwesha Banerjee, Bethany L. Sauls and Anna A. Morales have bred and maintained the animal colonies and litter details including litter size and litter survival within this study. Anwesha Banerjee performed the fear conditioning, open field, sensory modalities and social interaction experiments. Anwesha Banerjee, Bethany L. Sauls, Anna A. Morales performed the object recognition tests. Bethany L. Sauls, Anna A. Morales performed blind data scoring for foot shock sensitivity and paw lick test. Crystal T. Engineer and Michael P. Kilgard have conceived and carried out the tone threshold experiment. Anwesha Banerjee and Jonathan E. Ploski conceived the study and participated in its design and coordination and drafted the manuscript. All authors read, edited and approved the final manuscript.

\section{ACKNOWLEDGMENTS}

We thank Jonathan A. Luong, Sophia Moss for their assistance with the behavior experiments and Matthew P. Hosek for editorial feedback. Supported by NIH grants RMH096202A(Jonathan E. Ploski), RMH100650A(Jonathan E. Ploski), R01DC010433(Michael P. Kilgard) and the University of Texas at Dallas.

\section{SUPPLEMENTARY MATERIAL}

The Supplementary Material for this article can be found online at: http://www.frontiersin.org/journal/10.3389/fnbeh. 2014.00387/abstract

Table S1 | The table depicts the number of litters per cohort of animals per treatment, with each experiment and order of experiments performed on each cohort of animals listed.

Image 1 | Progeny from VPA-Hi exposed dams exhibit deficits in auditory

fearing conditioning. Progeny from VPA-Hi and saline exposed dams were auditory fear conditioned (Cohort 1 : Saline $=8, \mathrm{VPA}-\mathrm{Hi}=7$, Cohort 2:

Saline $=8, \mathrm{VPA}-\mathrm{Hi}=6$. (A) Pre and post-shock freezing was assessed immediately before and after exposure to tone-shock pairing in VPA-Hi cohort 1 animals. (B) Auditory fear memory assessed $24 \mathrm{~h}$ post fear conditioning (i.e., LTM) in VPA-Hi cohort 1 animals. (C) Pre and post-shock freezing was assessed immediately before and after exposure to tone-shock pairing in VPA-Hi cohort 2 animals. (D) Auditory fear memory assessed $24 \mathrm{~h}$ post fear conditioning in VPA-Hi cohort 2 animals (i.e., LTM). Bars represent the mean \pm standard error of the mean (SEM) $(* p<0.05)$.

\section{REFERENCES}

Adachi, M., Autry, A. E., Covington, H. E. 3rd., and Monteggia, L. M. (2009). MeCP2-mediated transcription repression in the basolateral amygdala may underlie heightened anxiety in a mouse model of Rett syndrome. J. Neurosci. 29, 4218-4227. doi: 10.1523/JNEUROSCI.4225-08.2009

Amir, R. E., Van Den Veyver, I. B., Wan, M., Tran, C. Q., Francke, U., and Zoghbi, H. Y. (1999). Rett syndrome is caused by mutations in X-linked MECP2, encoding methyl-CpG-binding protein 2. Nat. Genet. 23, 185-188. doi: 10.1038/13810

Arndt, T. L., Stodgell, C. J., and Rodier, P. M. (2005). The teratology of autism. Int. J. Dev. Neurosci. 23, 189-199. doi: 10.1016/j.ijdevneu.2004.11.001

Bachevalier, J., and Loveland, K. A. (2006). The orbitofrontal-amygdala circuit and self-regulation of social-emotional behavior in autism. Neurosci. Biobehav. Rev. 30, 97-117. doi: 10.1016/j.neubiorev.2005.07.002

Bailey, A., Le Couteur, A., Gottesman, I., Bolton, P., Simonoff, E., Yuzda, E., et al. (1995). Autism as a strongly genetic disorder: evidence from a British twin study. Psychol. Med. 25, 63-77. doi: 10.1017/S0033291700028099

Bambini-Junior, V., Rodrigues, L., Behr, G. A., Moreira, J. C., Riesgo, R., and Gottfried, C. (2011). Animal model of autism induced by prenatal exposure to valproate: behavioral changes and liver parameters. Brain Res. 1408, 8-16. doi: 10.1016/j.brainres.2011.06.015

Bernier, R., Dawson, G., Panagiotides, H., and Webb, S. (2005). Individuals with autism spectrum disorder show normal responses to a fear potential startle paradigm. J. Autism Dev. Disord. 35, 575-583. doi: 10.1007/s10803-005-0002-0

Binkerd, P. E., Rowland, J. M., Nau, H., and Hendrickx, A. G. (1988). Evaluation of valproic acid (VPA) developmental toxicity and pharmacokinetics in Sprague-Dawley rats. Fundam. Appl. Toxicol. 11, 485-493. doi: 10.1016/02720590(88)90112-1

Centanni, T. M., Booker, A. B., Sloan, A. M., Chen, F., Maher, B. J., Carraway, R. S., et al. (2014). Knockdown of the dyslexia-associated gene Kiaa0319 impairs temporal responses to speech stimuli in rat primary auditory cortex. Cereb. Cortex 24, 1753-1766. doi: 10.1093/cercor/bht028

Charman, T., Pickles, A., Simonoff, E., Chandler, S., Loucas, T., and Baird, G. (2011). IQ in children with autism spectrum disorders: data from the Special Needs and Autism Project (SNAP). Psychol. Med. 41, 619-627. doi: 10.1017/S0033291710000991

Chevallier, C., Kohls, G., Troiani, V., Brodkin, E. S., and Schultz, R. T. (2012). The social motivation theory of autism. Trends Cogn. Sci. 16, 231-239. doi: 10.1016/j.tics.2012.02.007

Chomiak, T., Hung, J., Cihal, A., Dhaliwal, J., Baghdadwala, M. I., Dzwonek, A., et al. (2014). Auditory-cued sensorimotor task reveals disengagement deficits in rats exposed to the autism-associated teratogen valproic acid. Neuroscience 268, 212-220. doi: 10.1016/j.neuroscience.2014.02.049

Christianson, A. L., Chesler, N., and Kromberg, J. G. (1994). Fetal valproate syndrome: clinical and neuro-developmental features in two sibling pairs. Dev. Med. Child Neurol. 36, 361-369. doi: 10.1111/j.1469-8749.1994.tb11858.x

Cohen, O. S., Varlinskaya, E. I., Wilson, C. A., Glatt, S. J., and Mooney, S. M. (2013). Acute prenatal exposure to a moderate dose of valproic acid increases social behavior and alters gene expression in rats. Int. J. Dev. Neurosci. 31, 740-750. doi: 10.1016/j.ijdevneu.2013.09.002

Downing, C., Biers, J., Larson, C., Kimball, A., Wright, H., Ishii, T., et al. (2010). Genetic and maternal effects on valproic acid teratogenesis in C57BL/6J and DBA/2J mice. Toxicol. Sci. 116, 632-639. doi: 10.1093/toxsci/kfq140

Edalatmanesh, M. A., Nikfarjam, H., Vafaee, F., and Moghadas, M. (2013). Increased hippocampal cell density and enhanced spatial memory in the valproic acid rat model of autism. Brain Res. 1526, 15-25. doi: 10.1016/j.brainres.2013.06.024

Engineer, C. T., Centanni, T. M., Im, K. W., Borland, M. S., Moreno, N. A., Carraway, R. S., et al. (2014a). Degraded auditory processing in a rat model of autism limits the speech representation in non-primary auditory cortex. Dev. Neurobiol. 74, 972-986. doi: 10.1002/dneu.22175

Engineer, C. T., Centanni, T. M., Im, K. W., Rahebi, K. C., Buell, E. P., and Kilgard, M. P. (2014b). Degraded speech sound processing in a rat model of fragile X syndrome. Brain Res. 1564, 72-84. doi: 10.1016/j.brainres.2014. 03.049

Evans, D. W., Canavera, K., Kleinpeter, F. L., Maccubbin, E., and Taga, K. (2005). The fears, phobias and anxieties of children with autism spectrum disorders and Down syndrome: comparisons with developmentally and chronologically age matched children. Child Psychiatry Hum. Dev. 36, 3-26. doi: 10.1007/s10578004-3619-x 
Eyal, S., Yagen, B., Sobol, E., Altschuler, Y., Shmuel, M., and Bialer, M. (2004). The activity of antiepileptic drugs as histone deacetylase inhibitors. Epilepsia 45, 737-744. doi: 10.1111/j.0013-9580.2004.00104.x

Favre, M. R., Barkat, T. R., Lamendola, D., Khazen, G., Markram, H., and Markram, K. (2013). General developmental health in the VPA-rat model of autism. Front. Behav. Neurosci. 7:88. doi: 10.3389/fnbeh.2013.00088

Fernandez, S. M., Lewis, M. C., Pechenino, A. S., Harburger, L. L., Orr, P. T., Gresack, J. E., et al. (2008). Estradiol-induced enhancement of object memory consolidation involves hippocampal extracellular signal-regulated kinase activation and membrane-bound estrogen receptors. J. Neurosci. 28, 8660-8667. doi: 10.1523/JNEUROSCI.1968-08.2008

Frick, K. M., and Gresack, J. E. (2003). Sex differences in the behavioral response to spatial and object novelty in adult C57BL/6 mice. Behav. Neurosci. 117, 1283-1291. doi: 10.1037/0735-7044.117.6.1283

Frisch, C., Husch, K., Angenstein, F., Kudin, A., Kunz, W., Elger, C. E., et al. (2009). Dose-dependent memory effects and cerebral volume changes after in utero exposure to valproate in the rat. Epilepsia 50, 1432-1441. doi: 10.1111/j.15281167.2008.01943.x

Gaigg, S. B., and Bowler, D. M. (2007). Differential fear conditioning in Asperger's syndrome: implications for an amygdala theory of autism. Neuropsychologia 45, 2125-2134. doi: 10.1016/j.neuropsychologia.2007.01.012

Golden, S. A., Covington, H. E. 3rd., Berton, O., and Russo, S. J. (2011). A standardized protocol for repeated social defeat stress in mice. Nat. Protoc. 6, 1183-1191. doi: 10.1038/nprot.2011.361

Gould, T. D., Quiroz, J. A., Singh, J., Zarate, C. A., and Manji, H. K. (2004). Emerging experimental therapeutics for bipolar disorder: insights from the molecular and cellular actions of current mood stabilizers. Mol. Psychiatry 9, 734-755. doi: 10.1038/sj.mp.4001518

Green, M. R., Barnes, B., and Mccormick, C. M. (2013a). Social instability stress in adolescence increases anxiety and reduces social interactions in adulthood in male Long-Evans rats. Dev. Psychobiol. 55, 849-859. doi: 10.1002/dev.21077

Green, S. A., Rudie, J. D., Colich, N. L., Wood, J. J., Shirinyan, D., Hernandez, L., et al. (2013b). Overreactive brain responses to sensory stimuli in youth with autism spectrum disorders. J. Am. Acad. Child Adolesc. Psychiatry 52, 1158-1172. doi: 10.1016/j.jaac.2013.08.004

Haberland, M., Montgomery, R. L., and Olson, E. N. (2009). The many roles of histone deacetylases in development and physiology: implications for disease and therapy. Nat. Rev. Genet. 10, 32-42. doi: 10.1038/nrg2485

Hallmayer, J., Cleveland, S., Torres, A., Phillips, J., Cohen, B., Torigoe, T., et al. (2011). Genetic heritability and shared environmental factors among twin pairs with autism. Arch. Gen. Psychiatry 68, 1095-1102. doi: 10.1001/archgenpsychiatry. 2011.76

Ingram, J. L., Peckham, S. M., Tisdale, B., and Rodier, P. M. (2000). Prenatal exposure of rats to valproic acid reproduces the cerebellar anomalies associated with autism. Neurotoxicol. Teratol. 22, 319-324. doi: 10.1016/S0892-0362(99) 00083-5

Jergil, M., Kultima, K., Gustafson, A. L., Dencker, L., and Stigson, M. (2009). Valproic acid-induced deregulation in vitro of genes associated in vivo with neural tube defects. Toxicol. Sci. 108, 132-148. doi: 10.1093/toxsci/kfp002

Kataoka, S., Takuma, K., Hara, Y., Maeda, Y., Ago, Y., and Matsuda, T. (2013). Autism-like behaviours with transient histone hyperacetylation in mice treated prenatally with valproic acid. Int. J. Neuropsychopharmacol. 16, 91-103. doi: 10.1017/S1461145711001714

Kemper, T. L., and Bauman, M. (1998). Neuropathology of infantile autism. J. Neuropathol. Exp. Neurol. 57, 645-652. doi: 10.1097/00005072-19980700000001

Kerr, D. M., Downey, L., Conboy, M., Finn, D. P., and Roche, M. (2013). Alterations in the endocannabinoid system in the rat valproic acid model of autism. Behav. Brain Res. 249, 124-132. doi: 10.1016/j.bbr.2013.04.043

Kilgard, M. P., and Merzenich, M. M. (1999). Distributed representation of spectral and temporal information in rat primary auditory cortex. Hear. Res. 134, 16-28. doi: 10.1016/S0378-5955(99)00061-1

Kim, K. C., Kim, P., Go, H. S., Choi, C. S., Yang, S. I., Cheong, J. H., et al. (2011). The critical period of valproate exposure to induce autistic symptoms in SpragueDawley rats. Toxicol. Lett. 201, 137-142. doi: 10.1016/j.toxlet.2010.12.018

Kultima, K., Jergil, M., Salter, H., Gustafson, A. L., Dencker, L., and Stigson, M. (2010). Early transcriptional responses in mouse embryos as a basis for selection of molecular markers predictive of valproic acid teratogenicity. Reprod. Toxicol. 30, 457-468. doi: 10.1016/j.reprotox.2010.05.014
Kwan, P., Sills, G. J., and Brodie, M. J. (2001). The mechanisms of action of commonly used antiepileptic drugs. Pharmacol. Ther. 90, 21-34. doi: 10.1016/S0163-7258(01)00122-X

Lazic, S. E., and Essioux, L. (2013). Improving basic and translational science by accounting for litter-to-litter variation in animal models. BMC Neurosci. 14:37. doi: 10.1186/1471-2202-14-37

Lin, H. C., Gean, P. W., Wang, C. C., Chan, Y. H., and Chen, P. S. (2013). The amygdala excitatory/inhibitory balance in a valproate-induced rat autism model. PLoS ONE 8:e55248. doi: 10.1371/journal.pone.0055248

Mao, R., Page, D. T., Merzlyak, I., Kim, C., Tecott, L. H., Janak, P. H., et al. (2009). Reduced conditioned fear response in mice that lack Dlx1 and show subtype-specific loss of interneurons. J. Neurodev. Disord. 1, 224-236. doi: 10.1007/s11689-009-9025-8

Markram, K., Rinaldi, T., La Mendola, D., Sandi, C., and Markram, H. (2008). Abnormal fear conditioning and amygdala processing in an animal model of autism. Neuropsychopharmacology 33, 901-912. doi: 10.1038/sj.npp.1301453

Marshall, C. R., Noor, A., Vincent, J. B., Lionel, A. C., Feuk, L., Skaug, J., et al. (2008). Structural variation of chromosomes in autism spectrum disorder. Am. J. Hum. Genet. 82, 477-488. doi: 10.1016/j.ajhg.2007.12.009

Martin, H. G., and Manzoni, O. J. (2014). Late onset deficits in synaptic plasticity in the valproic acid rat model of autism. Front. Cell. Neurosci. 8:23. doi: $10.3389 /$ fncel.2014.00023

Miller, J. N., and Ozonoff, S. (2000). The external validity of Asperger disorder: lack of evidence from the domain of neuropsychology. J. Abnorm. Psychol. 109, 227-238. doi: 10.1037/0021-843X.109.2.227

Moldrich, R. X., Leanage, G., She, D., Dolan-Evans, E., Nelson, M., Reza, N., et al. (2013). Inhibition of histone deacetylase in utero causes sociability deficits in postnatal mice. Behav. Brain Res. 257, 253-264. doi: 10.1016/j.bbr.2013.09.049

Montgomery, R. L., Hsieh, J., Barbosa, A. C., Richardson, J. A., and Olson, E. N. (2009). Histone deacetylases 1 and 2 control the progression of neural precursors to neurons during brain development. Proc. Natl. Acad. Sci. U.S.A. 106, 7876-7881. doi: 10.1073/pnas.0902750106

Moore, S. J., Turnpenny, P., Quinn, A., Glover, S., Lloyd, D. J., Montgomery, T., et al. (2000). A clinical study of 57 children with fetal anticonvulsant syndromes. J. Med. Genet. 37, 489-497. doi: 10.1136/jmg.37.7.489

Munson, J., Dawson, G., Sterling, L., Beauchaine, T., Zhou, A., Elizabeth, K., et al. (2008). Evidence for latent classes of IQ in young children with autism spectrum disorder. Am. J. Ment. Retard. 113, 439-452. doi: 10.1352/2008.113:439-452

Ogawa, T., Kuwagata, M., Hori, Y., and Shioda, S. (2007). Valproate-induced developmental neurotoxicity is affected by maternal conditions including shipping stress and environmental change during early pregnancy. Toxicol. Lett. 174, 18-24. doi: 10.1016/j.toxlet.2007.08.006

Oguchi-Katayama, A., Monma, A., Sekino, Y., Moriguchi, T., and Sato, K. (2013). Comparative gene expression analysis of the amygdala in autistic rat models produced by pre- and post-natal exposures to valproic acid. J. Toxicol. Sci. 38, 391-402. doi: 10.2131/jts.38.391

Perez, C. A., Engineer, C. T., Jakkamsetti, V., Carraway, R. S., Perry, M. S., and Kilgard, M. P. (2013). Different timescales for the neural coding of consonant and vowel sounds. Cereb. Cortex 23, 670-683. doi: 10.1093/cercor/bhs045

Phiel, C. J., Zhang, F., Huang, E. Y., Guenther, M. G., Lazar, M. A., and Klein, P. S. (2001). Histone deacetylase is a direct target of valproic acid, a potent anticonvulsant, mood stabilizer, and teratogen. J. Biol. Chem. 276, 36734-36741. doi: 10.1074/jbc.M101287200

Polley, D. B., Read, H. L., Storace, D. A., and Merzenich, M. M. (2007). Multiparametric auditory receptive field organization across five cortical fields in the albino rat. J. Neurophysiol. 97, 3621-3638. doi: 10.1152/jn.01298.2006

Rasalam, A. D., Hailey, H., Williams, J. H., Moore, S. J., Turnpenny, P. D., Lloyd, D. J., et al. (2005). Characteristics of fetal anticonvulsant syndrome associated autistic disorder. Dev. Med. Child Neurol. 47, 551-555. doi: 10.1017/S0012162205001076

Rodier, P. M., Ingram, J. L., Tisdale, B., and Croog, V. J. (1997). Linking etiologies in humans and animal models: studies of autism. Reprod. Toxicol. 11, 417-422. doi: 10.1016/S0890-6238(97)80001-U

Rodier, P. M., Ingram, J. L., Tisdale, B., Nelson, S., and Romano, J. (1996). Embryological origin for autism: developmental anomalies of the cranial nerve motor nuclei. J. Comp. Neurol. 370, 247-261.

Schneider, T., and Przewlocki, R. (2005). Behavioral alterations in rats prenatally exposed to valproic acid: animal model of autism. Neuropsychopharmacology 30, 80-89. doi: 10.1038/sj.npp.1300518 
Schneider, T., Roman, A., Basta-Kaim, A., Kubera, M., Budziszewska, B., Schneider, K., et al. (2008). Gender-specific behavioral and immunological alterations in an animal model of autism induced by prenatal exposure to valproic acid. Psychoneuroendocrinology 33, 728-740. doi: 10.1016/j.psyneuen.2008. 02.011

Schneider, T., Ziolkowska, B., Gieryk, A., Tyminska, A., and Przewlocki, R. (2007). Prenatal exposure to valproic acid disturbs the enkephalinergic system functioning, basal hedonic tone, and emotional responses in an animal model of autism. Psychopharmacology (Berl) 193, 547-555. doi: 10.1007/s00213-0070795-y

Schultz, R. T. (2005). Developmental deficits in social perception in autism: the role of the amygdala and fusiform face area. Int. J. Dev. Neurosci. 23, 125-141. doi: 10.1016/j.ijdevneu.2004.12.012

Shaked, M., Weissmuller, K., Svoboda, H., Hortschansky, P., Nishino, N., Wolfl, S., et al. (2008). Histone deacetylases control neurogenesis in embryonic brain by inhibition of BMP2/4 signaling. PLOS ONE 3:e2668. doi: 10.1371/journal.pone. 0002668

South, M., Larson, M. J., White, S. E., Dana, J., and Crowley, M. J. (2011). Better fear conditioning is associated with reduced symptom severity in autism spectrum disorders. Autism Res. 4, 412-421. doi: 10.1002/aur.221

South, M., Newton, T., and Chamberlain, P. D. (2012). Delayed reversal learning and association with repetitive behavior in autism spectrum disorders. Autism Res. 5, 398-406. doi: 10.1002/aur.1255

Sui, L., and Chen, M. (2012). Prenatal exposure to valproic acid enhances synaptic plasticity in the medial prefrontal cortex and fear memories. Brain Res. Bull. 87, 556-563. doi: 10.1016/j.brainresbull.2012.01.011

Umeda, T., Takashima, N., Nakagawa, R., Maekawa, M., Ikegami, S., Yoshikawa, T., et al. (2010). Evaluation of Pax6 mutant rat as a model for autism. PLoS ONE 5:e15500. doi: 10.1371/journal.pone.0015500

Vajda, F. J., O’brien, T., J., Hitchcock, A., Graham, J., Cook, M., Lander, C., et al. (2004). Critical relationship between sodium valproate dose and human teratogenicity: results of the Australian register of anti-epileptic drugs in pregnancy. J. Clin. Neurosci. 11, 854-858. doi: 10.1016/j.jocn.2004. 05.003
Vorhees, C. V. (1987). Behavioral teratogenicity of valproic acid: selective effects on behavior after prenatal exposure to rats. Psychopharmacology (Berl) 92, 173-179. doi: 10.1007/BF00177911

Wang, C. C., Lin, H. C., Chan, Y. H., Gean, P. W., Yang, Y. K., and Chen, P. S. (2013). 5-HT1A-receptor agonist modified amygdala activity and amygdalaassociated social behavior in a valproate-induced rat autism model. Int. J. Neuropsychopharmacol. 16, 2027-2039. doi: 10.1017/S1461145713000473

Weisbrot, D. M., Gadow, K. D., Devincent, C. J., and Pomeroy, J. (2005). The presentation of anxiety in children with pervasive developmental disorders. J. Child Adolesc. Psychopharmacol. 15, 477-496. doi: 10.1089/cap.2005.15.477

Wolff, J. J., and Symons, F. J. (2013). An evaluation of multi-component exposure treatment of needle phobia in an adult with autism and intellectual disability. J. Appl. Res. Intellect. Disabil. 26, 344-348. doi: 10.1111/jar.12002

Zhao, M. G., Toyoda, H., Ko, S. W., Ding, H. K., Wu, L. J., and Zhuo, M. (2005). Deficits in trace fear memory and long-term potentiation in a mouse model for fragile X syndrome. J. Neurosci. 25, 7385-7392. doi: 10.1523/JNEUROSCI.152005.2005

Conflict of Interest Statement: The authors declare that the research was conducted in the absence of any commercial or financial relationships that could be construed as a potential conflict of interest.

Received: 30 June 2014; accepted: 17 October 2014; published online: 12 November 2014.

Citation: Banerjee A, Engineer CT, Sauls BL, Morales AA, Kilgard MP and Ploski JE (2014) Abnormal emotional learning in a rat model of autism exposed to valproic acid in utero. Front. Behav. Neurosci. 8:387. doi: 10.3389/fnbeh.2014.00387

This article was submitted to the journal Frontiers in Behavioral Neuroscience. Copyright (c) 2014 Banerjee, Engineer, Sauls, Morales, Kilgard and Ploski. This is an open-access article distributed under the terms of the Creative Commons Attribution License (CC BY). The use, distribution or reproduction in other forums is permitted, provided the original author(s) or licensor are credited and that the original publication in this journal is cited, in accordance with accepted academic practice. No use, distribution or reproduction is permitted which does not comply with these terms. 